\author{
Tadeusz ORZECHOWSKI ${ }^{1}$ \\ Sylwia WCIŚLIK ${ }^{2}$
}

\title{
STUDIUM KSZTAŁTU KROPLI WODY W WARUNKACH LEIDENFROSTA
}

\begin{abstract}
Praca dotyczy odparowania dużych kropel cieczy o masie $\sim 1 \mathrm{~g} \mathrm{w}$ warunkach stabilnego wrzenia błonowego pod ciśnieniem atmosferycznym. Odparowanie kropli cieczy unoszącej się nad gorącą powierzchnią o temperaturze powyżej punktu Leidenfrosta jest zjawiskiem bardzo trudnym do dokładnego opisu teoretycznego. Przeprowadzone badania wskazują na złożony charakter wzajemnie powiązanych procesów wymiany ciepła i masy, które prowadzą do intensywnych przypowierzchniowych ruchów konwekcyjnych wewnątrz kropli. Obrazem tego jest silne zróżnicowanie pola termalnego górnej powierzchni kropli. Można tam zauważyć, że przy średniej temperaturze kropli $\sim 91^{\circ} \mathrm{C}$ różnica pomiędzy skrajnymi temperaturami może dochodzić nawet do $\sim 8 \mathrm{~K}$.
\end{abstract}

Słowa kluczowe: wrzenie błonowe, kropla Leidenfrosta, kamera termowizyjna, niestabilność kształtu, ruchy konwekcyjne

\section{Przegląd aktualnego stanu wiedzy}

Odparowanie kropli wody położonej na gorącej powierzchni ma wielkie znaczenie $w$ wielu procesach przemysłowych, m.in. w energetyce jądrowej, silnikach odrzutowych i rakietowych [1], [2], odparowaniu paliw w silnikach spalinowych [3], przemyśle metalurgicznym, chłodzeniu łopatek turbin i aparatury [4], w chłodniach kominowych i innych.

Kropla cieczy odparowująca z powierzchni o temperaturze powyżej drugiego punktu krytycznego jest zjawiskiem, w którym ilość produkowanej pary jest wystarczająca do wytworzenia siły nośnej podtrzymującej kroplę. W takim przypadku praktycznie nie obserwuje się zwilżenia powierzchni ze względu na po-

\footnotetext{
1 Autor do korespondencji/corresponding author: Tadeusz Orzechowski, Politechnika Świętokrzyska, al. Tysiąclecia Państwa Polskiego 7, 25-314 Kielce, tel. 413424 854, e-mail: todek@tu.kielce.pl

${ }^{2}$ Sylwia Wciślik, e-mail: sylwiazw@tu.kielce.pl
} 
duszkę parową na której jest unoszona. Jej sferyczny kształt odpowiada minimum energii powierzchniowej.

Wpływ warunków powierzchniowych na osiągnięcie przez ciecz warunków krytycznych omawiane jest w pracy [5]. Stwierdza się tam, że odparowująca na powierzchni ciała stałego kropla cieczy uważana jest za powierzchnię silnie zakrzywioną. W zależności od warunków wymiany ciepła i kształtów przybieranych przez taką kroplę, obserwuje się wewnętrzne ruchy konwekcyjne. W [6] przedstawiono technikę rekonstrukcji obrazu do wizualizacji przepływu wewnątrz małych parujących kropel przy wykorzystaniu metody śledzenia promienia (Ray-Tracing). Przedstawione tam badania symulacyjne sugerują, że ruchy konwekcyjne wewnątrz parującej kropli cieczy są rozłożone symetrycznie, a zatem problem należy rozpatrywać $w$ kategorii osiowosymetrycznych. Podobne wnioski znaleźć też można w pracy [7]. Przeprowadzone badania własne wyraźnie zaprzeczają takiemu stwierdzeniu, co również potwierdzają inne prace badawcze, w których zamieszczono mapy odwzorowujące życie kropli np. [8].

W celu dynamicznego odwzorowania zachowania się pojedynczej kropli cieczy podczas odparowania na powierzchni poziomej często wykorzystuje się termowizję, np. w [9]. Opisane tam badania obejmowały trzy zakresy odparowania kropli: pierwszy - podgrzanie cieczy od temperatury otoczenia do $\sim 44^{\circ} \mathrm{C}$, drugi - odparowywanie kropli i ujawnienie niestabilności związanych z procesem konwekcji wewnętrznej, trzeci - odparowywanie kropli przy braku niestabilności charakteryzujące się zmniejszeniem gęstości odprowadzanego ciepła. Powstawanie niestabilności konwekcyjnych tłumaczy się wysokim przegrzaniem. Autorzy sugerują konieczność prowadzenia dalszych badań nad wspomnianymi niestabilnościami w celu lepszego poznania natury tego zjawiska.

Jak wiadomo krople cieczy odparowujące na poziomej powierzchni ciała stałego w warunkach wrzenia błonowego przybierają różne kształty. W pracy [10] przeprowadzono analizę literaturową, na podstawie czego postuluje się, że krople o objętości powyżej $1 \mathrm{~cm}^{3}$ przybierają kształt płaskiego dysku, a mniejsze od $0,5 \mathrm{~mm}^{3}$ są sferyczne.

Na przykładzie położonej na gorącej powierzchni kropli o temperaturze bliskiej punktowi Leidenfrosta w [11] wykazano również, że proces odparowania może być niezależnie opisywany w zakresie dwóch kształtów kropli - sferoidu i kuli. Celem tych badań było określenie czasu odparowania kropli. Prezentowane w [11] wyniki wskazują na pewną rozbieżność z wcześniejszymi podawanymi przez Baumeistera [12].

Jedna z najnowszych prac [13] dotyczących analizy geometrii warstwy parowej pod kroplą Leidenfrosta wykorzystuje światło monochromatyczne. Badania prowadzono na kroplach o różnych wielkościach i kształtach, które odparowywano na powierzchni grzejnej o temperaturze od 245 do $370^{\circ} \mathrm{C}$ pod ciśnieniem atmosferycznym. 
Na podstawie obserwacji zjawiska i przeprowadzonych obliczeń stwierdzono, że maksymalny promień kropli $\mathrm{R}_{\max }$ oraz promień przewężenia kropli parą $R_{\text {neck }}$ silnie zależą od grawitacji i napięcia powierzchniowego. Zauważono również, że wysokość kieszeni parowej pomiędzy kroplą, a powierzchnią $\mathrm{h}_{\text {neck }}$ zależy jedynie od strumienia wypływającej spod kropli pary, a więc od wielkości kropli, a kształt kieszeni parowej prawie nie ma związku z temperaturą powierzchni grzejnej. Ponadto, w pracy [13] pominięto ruchy wewnętrzne w kropli, a przedstawione wnioski nie odnoszą się do kropli większych, dla których $\mathrm{R}_{\max }>\sim 9 \mathrm{~mm}$. $\mathrm{Z}$ punktu widzenia fizycznego, ze względu na niejednorodność zaobserwowanego obrazu powierzchni dużych kropel, w [13] nie podjęto próby jednoznacznego opisania zjawiska odparowania.

Niniejsza praca dotyczy analizy kształtu kropli cieczy odparowującej $\mathrm{z}$ powierzchni miedzianego walca grzejnego $\mathrm{w}$ warunkach wrzenia błonowego ze szczególnym uwzględnieniem konwekcyjnych ruchów podpowierzchniowych w kropli, które wpływają na niesymetryczny charakter zjawiska. W tym celu zestawiono stanowisko badawcze oparte o pomiar aktualnej masy kropli oraz termowizyjną analizę jej kształtu.

\section{Aparatura pomiarowa}

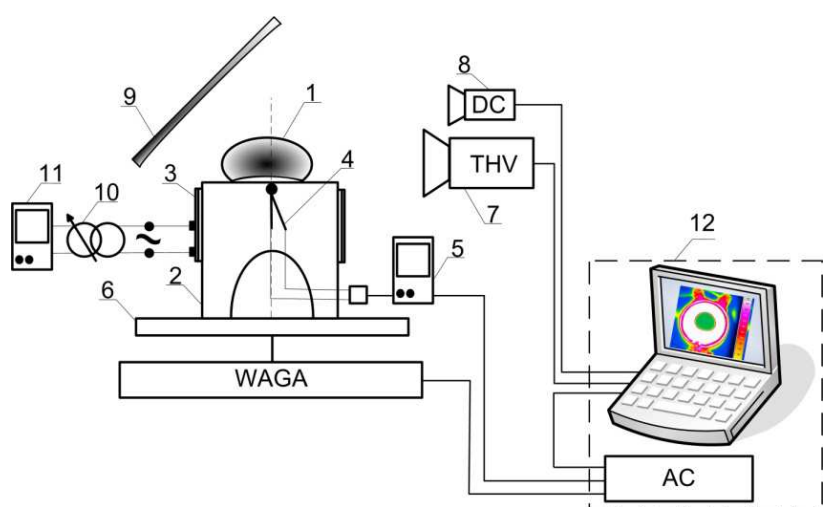

Rys. 1. Aparatura pomiarowa do badania odparowania kropli cieczy z powierzchni o temperaturze powyżej punktu Leidenfrosta; 1 - kropla wody, 2 - walec grzejny, 3 - grzałka opaskowa, 4 termopara, 5 - miernik (pomiar temperatury), 6 - waga elektroniczna AXIS AG500, 7 - kamera termowizyjna VarioCAM hr, 8 - aparat cyfrowy, 9 - lustro, 10 - autotransformator, 11 - woltomierz, 12 - układ cyfrowej akwizycji i przetwarzania danych (zestaw kart AC i komputer)

Fig. 1. Test apparatus for testing of liquid drop evaporation from the surface with a temperature above the Leidenfrost's point; 1 - a drop of water, 2 - heating cylinder, 3 - band heater, 4 - thermocouple, 5 - measuring instrument (temperature measurement), 6 - AXIS AG500 electronic scale, 7 - VarioCAM hr infrared camera, 8 - digital camera, 9 - mirror, 10 - autotransformer, 11 voltmeter, 12 - system of digital acquisition and data processing (computer PC and the set of AC cards) 
Stanowiska pomiarowe do badania odparowania kropli wody o masie i średnicy początkowej wynoszącej odpowiednio $\sim 1 \mathrm{~g} \mathrm{i} \sim 1 \mathrm{~cm} \mathrm{z}$ powierzchni o temperaturze powyżej punktu Leidenfrosta pokazano na rys. 1. Zestawione stanowisko składa się z trzech niezależnych torów pomiarowych: kamery, wagi i temperatury. Wynikiem pomiaru jest chwilowy ubytek masy kropli, temperatura zewnętrznej i widocznej powierzchni kropli oraz powierzchni grzejnej oraz prostopadły rzut kropli na powierzchnię grzejną. Rejestrację pomiarów uruchamiano przy wadze pojedynczej kropli wynoszącej $\sim 1$ g. Częstotliwość rejestracji masy kropli i termogramów ustawiono na $2 \mathrm{~Hz}$. Całkowity czas odparowania kropel wynosił kilka minut dla przyjętych średnich temperatur powierzchni z zakresu: $\mathrm{T}_{\mathrm{w}} \approx 298^{\circ} \mathrm{C} \div 404^{\circ} \mathrm{C}$. Dokładny opis procedury i metodyki badawczej zamieszczono $\mathrm{w}[14]$.

\section{Analiza kształtu kropli}

Na stanowisku badawczym, którego schemat przedstawiono na rys. 1 przeprowadzono serię ponad 30 pomiarów dla każdej z analizowanych temperatur powierzchni. Jednym z uzyskanych wyników jest temperatura kropli $\left(\mathrm{T}_{\mathrm{d}}\right)$, którą oszacowano na podstawie termogramów sporządzonych przy pomocy oprogramowania Irbis Professional obsługującego kamerę termowizyjną. Współczynnik emisyjności dla wody przyjęto równy $\varepsilon_{1}=0,96$. Wielkość temperatury $T_{d}$ przyjęto jako wartość średnią z obserwowanej kamerą górnej powierzchni kropli. Dla przykładowej temperatury powierzchni grzejnej $\left(\mathrm{T}_{\mathrm{w}}=310,5^{\circ} \mathrm{C}\right)$, średnia temperatura kropli jest ok. $10^{\circ} \mathrm{C}$ niższa od temperatury saturacji i wynosi $\mathrm{T}_{\mathrm{d}}=$ $90,6^{\circ} \mathrm{C}$. Wielkość tę oszacowana dla pierwszych 200 sekund pomiaru z krokiem czasowym $\Delta \mathrm{t}=0,5 \mathrm{~s}$. Warto dodać, że temperatura kropli wykazuje dużą zmienność powierzchniową, co świadczy o silnych ruchach konwekcyjnych wewnątrz niej.

Tablica 1. Deskryptory statystyczne odnoszące się do rys. 2

Table 1. Statistical descriptors corresponding to Fig. 2

\begin{tabular}{|c|c|c|c|c|c|}
\hline L.p. & $\mathbf{t}, \mathbf{s}$ & Śrdnia, $^{\mathbf{}} \mathbf{C}$ & Min, $^{\mathbf{}} \mathbf{C}$ & Max, $^{\mathbf{}} \mathbf{C}$ & SD, $^{\mathbf{}} \mathbf{C}$ \\
\hline a & 0 & 91,07 & 90,93 & 91,29 & 0,09 \\
\hline b & 2,5 & 92,23 & 91,88 & 92,69 & 0,22 \\
\hline c & 5 & 91,75 & 91,36 & 92,12 & 0,17 \\
\hline d & 15 & 92,08 & 91,81 & 92,38 & 0,15 \\
\hline e & 70 & 86,29 & 86,04 & 86,46 & 0,1 \\
\hline f & 75 & 88,14 & 87,69 & 88,6 & 0,24 \\
\hline g & 85 & 88,36 & 87,61 & 89,14 & 0,5 \\
\hline h & 95 & 89,75 & 88,97 & 90,18 & 0,33 \\
\hline i & 145 & 91,29 & 90,37 & 92,06 & 0,46 \\
\hline j & 150 & 91,82 & 91,35 & 92,20 & 0,22 \\
\hline k & 155 & 92,96 & 92,61 & 93,28 & 0,17 \\
\hline l & 165 & 92,92 & 92,47 & 93,49 & 0,25 \\
\hline
\end{tabular}


a)

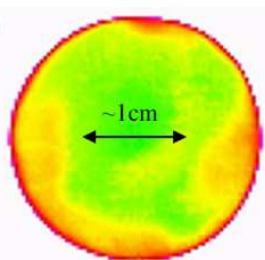

e)

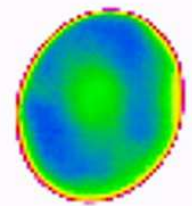

i)

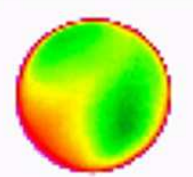

b)

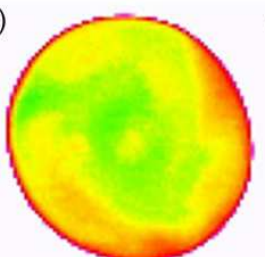

f)

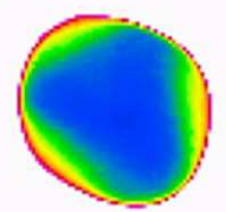

j)

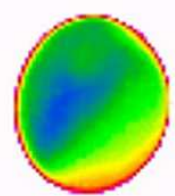

c)

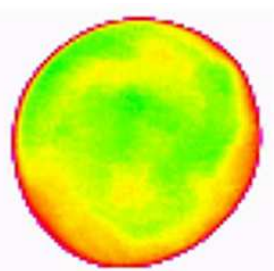

g)

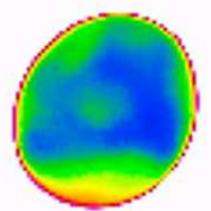

k)

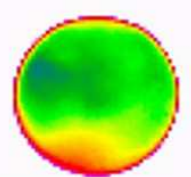

d)

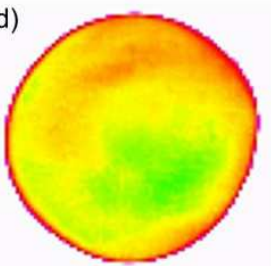

h)

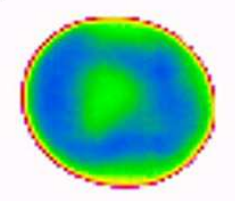

I)

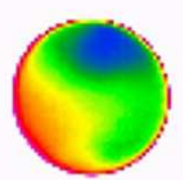

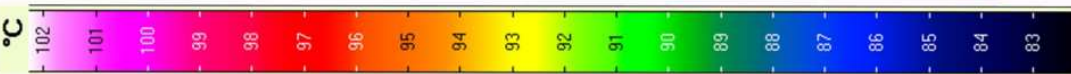

Rys. 2. Termogramy obrazujące rzut kropli na powierzchnię grzejną dla przykładowej temperatury powierzchni walca grzejnego, $\mathrm{T}_{\mathrm{w}}=310,5^{\circ} \mathrm{C}$

Fig. 2. The thermograms of the drop projection on the heating plate dfor exemplary temperature of theheating cylinder of $\mathrm{T}_{\mathrm{w}}=310,5^{\circ} \mathrm{C}$

Przykładowe termogramy powierzchni dla kropli o różnej wielkości pokazano na rys. 2, a w tab. 1 zamieszczono podstawowe deskryptory statystyczne odnoszące się do tych termogramów. Na podstawie zdjęć termowizyjnych wyznaczono minimalną $\mathrm{T}_{\mathrm{d}, \min }$, maksymalną $\mathrm{T}_{\mathrm{d} \text {, max }} \mathrm{i}$ średnią $\mathrm{T}_{\mathrm{d}}$ temperaturę $\mathrm{z}$ obszaru kropli w czasie pierwszych 200 sekund jej odparowania, które wynoszą odpowiednio $85,96^{\circ} \mathrm{C}, 93,75^{\circ} \mathrm{C}$ i $90,60^{\circ} \mathrm{C}$. Pozostałe deskryptory statystyczne zamieszczono w tab. 2.

Tablica 2. Zestawienie podstawowych deskryptorów statystycznych dotyczących temperatury kropli wody $\mathrm{w}$ analizowanym przypadku $\left(\mathrm{T}_{\mathrm{w}}=310,5^{\circ} \mathrm{C}\right)$

Table 2. Basic statistical descriptors concern water drop temperature $\left(\mathrm{T}_{\mathrm{w}}=310,5^{\circ} \mathrm{C}\right)$

\begin{tabular}{|c|l|c|c|c|c|}
\hline L.p. & \multicolumn{1}{|c|}{ Opis } & $\begin{array}{c}\text { T, } \\
{ }^{\mathbf{0}} \mathbf{C}\end{array}$ & $\begin{array}{c}\text { Min, } \\
{ }^{\mathbf{0}} \mathbf{C}\end{array}$ & $\begin{array}{c}\text { Max (T), } \\
{ }^{\mathbf{0}} \mathbf{C}\end{array}$ & $\begin{array}{c}\text { SD (T), } \\
{ }^{\mathbf{0}} \mathbf{C}\end{array}$ \\
\hline 1 & $\begin{array}{l}\text { Średnia ze średnich temperatur } \\
\text { kropli, } \mathrm{T}_{\mathrm{d}}\end{array}$ & 90,60 & 85,96 & 93,75 & 1,895 \\
\hline 2 & $\begin{array}{l}\text { Średnia z minimalnych tempe- } \\
\text { ratur kropli, }\end{array}$ & 90,20 & 85,33 & 93,42 & 1,903 \\
\hline 3 & $\begin{array}{l}\text { Średnia z maksymalnych } \\
\text { temperatur kropli, } \mathrm{T}_{\mathrm{d}, \max }\end{array}$ & 91,03 & 86,46 & 94,22 & 1,900 \\
\hline
\end{tabular}


W niektórych seriach pomiarowych zauważono, że w pewnych zakresach czasami pojawiają się wyraźne niestabilności objawiające się zmianą kształtu kropli i związanym z tym ruchem obrotowym wokół jej osi, co pokazano na rys. 3. Takie niestabilności powodują, że kropla zamiast przybierać kształt sferyczny, występuje w postaci wieloramiennej, bądź elipsoidalnej.
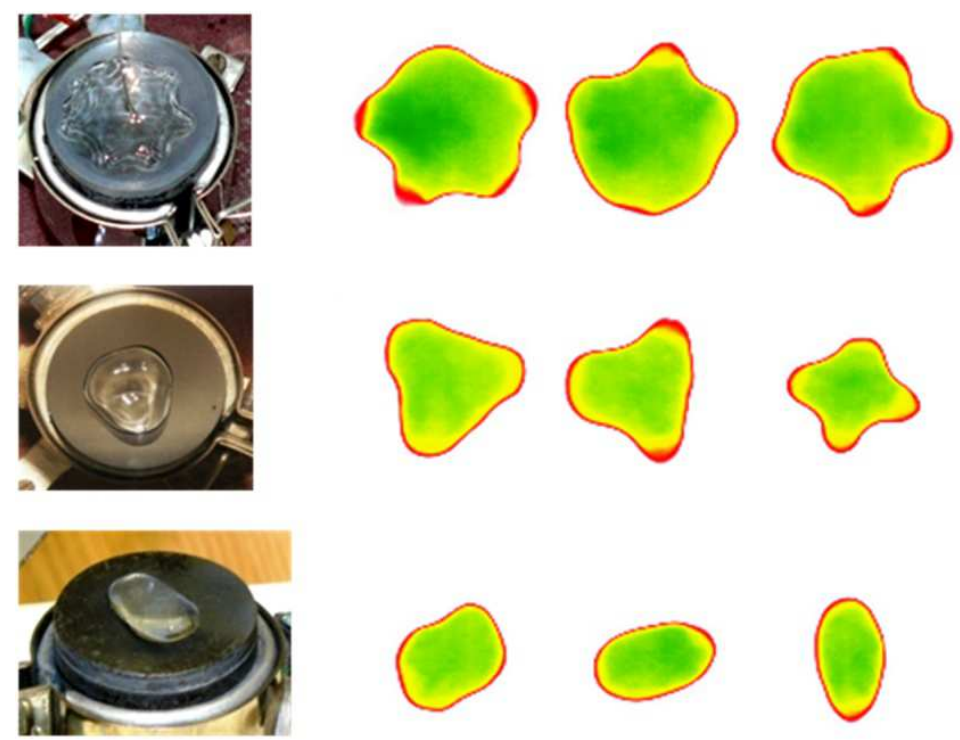

Rys. 3. Zdjęcia cyfrowe i termowizyjne pokazujące niestabilności kształtu kropli

Fig. 3. Digital and thermal images of instability of water drop shape

\section{Wnioski}

Złożony charakter wzajemnie powiązanych procesów wymiany ciepła i masy jest wynikiem niestabilnego w czasie wypływu pary spod dolnej powierzchni kropli, co prowadzi do intensywnych podpowierzchniowych ruchów konwekcyjnych. Obrazem tego jest zróżnicowanie pola termalnego górnej powierzchni kropli, które przykładowo zilustrowano na rys. 2. Można tam zauważyć, że przy średniej temperaturze kropli $\sim 91^{\circ} \mathrm{C}$ różnica pomiędzy skrajnymi temperaturami może dochodzić nawet do $\sim 8^{\circ} \mathrm{C}$ przy $\mathrm{T}_{\mathrm{w}}=310,5^{\circ} \mathrm{C}$.

Najistotniejszą, z punktu widzenia analizy doświadczalnej, jest wartość maksymalnego odchylenia standardowego od średniej temperatury kropli $\mathrm{T}_{\mathrm{d}}=90,60^{\circ} \mathrm{C}$, które dla temperatury powierzchni grzejnej $\mathrm{T}_{\mathrm{w}}=310,5^{\circ} \mathrm{C}$ wynosi $\mathrm{SD}=1,895^{\circ} \mathrm{C}$ i określone zostało z 401 wartości $\left(90,60^{\circ} \mathrm{C} \pm 1,9^{\circ} \mathrm{C}\right)$. 
Analiza przeprowadzona dla innych temperatur powierzchni grzejnej z zakresu $\mathrm{T}_{\mathrm{w}} \approx 298^{\circ} \mathrm{C} \div 404^{\circ} \mathrm{C}$, za każdym razem potwierdza tezę o zmienności warunków termicznych w obszarze kropli wody odparowującej $\mathrm{z}$ powierzchni w warunkach stabilnego wrzenia błonowego. Świadczą o tym wysokie wartości odchylenia standardowego od średniej temperatury kropli sięgające $\mathrm{SD} \approx 2^{\circ} \mathrm{C}$ i więcej. Ponadto, przemieszczająca się $\mathrm{z}$ dużą prędkością w obszarze kropli woda wskazuje na intensywne ruchy konwekcyjne o charakterze turbulentnym, co jest przyczyną niesymetrycznego kształtu (rys. 3). W związku z tym - spotykane w literaturze - osiowosymetryczne modelowanie kropli cieczy odparowującej z powierzchni w warunkach wrzenia błonowego są daleko idącym uproszczeniem rzeczywistego charakteru procesu.

Wymiana ciepła pomiędzy unoszoną kroplą a gorącą powierzchnią jest procesem złożonym i trudnym do opisu uwzględniającego złożony charakter ruchu fazy ciekłej. Możliwym jest natomiast ustalenie związków korelacyjnych na chwilowe wartości współczynnika przejmowania ciepła, co na przykładzie dużej kropli wody opisano w pracy [15].

\section{Literatura}

[1] Abramzon B., Sazhin S.: Droplet vaporization model in the presence of thermal radiation, Int. J. Heat Mass Transfer, 48 (2005) 1868-1873.

[2] Guang W., Sirignano W.A.: Transient convective burning of interactive fuel droplets in double-layer arrays, Combustion Flame, 158 (2011) 2395-2407.

[3] Sazhin S.S., Krutitskii P.A., Gusev I.G., Heikal M.R., Transient heating of an evaporating droplet, Int. J. Heat Mass Transfer, 53 (2010) 2826-2836.

[4] Bernardin J.D. et al.: Mapping of impact and heat transfer regimes of water drops impinging on polish surface, Int. J. Heat Mass Transfer, 40 (1997) 247-267.

[5] Nakoryakov V.E., Misyura S.Y., Elistratov S.L.: The behavior of water droplets on the heated surface, Int. J. Heat Mass Transfer, 55 (2012) 6609-6617.

[6] Kang K. H., Lee S. J., Lee C. M.: Visualization of flow inside a small evaporating droplet, 5th Int. Symposium Particle Image Velocimetry, paper 3242, Busan 2003.

[7] Arnim von V., McKinley G.H., Hosoi A.E., Tam D.: Marangoni convection in droplets on superhydrophobic surfaces, J. Fluid Mech., 624 (2009) 101-123.

[8] Fujimoto H., Oku Y., Ogihara T., Takuda H.: Hydrodynamics and boiling phenomena of water droplets impinging on hot solid, Int. J. Multiphase Flow, 36 (2010) 620642.

[9] Brutin D., Sobac B., Rigollet F., Le Niliot C.: Infrared visualization of thermal motion inside a sessile drop deposited onto a heated surface, Exp. Thermal Fluid Sci. 35 (2011) 521-530.

[10] Bleiker G., Specht E.: Film evaporation of drops of different shape above a horizontal plate, Int. J. Thermal Sci., vol. 46 (2007) 835-841.

[11] Xie H., Zhou Z.: A model for droplet evaporation near Leidenfrost point, Int. J. Heat Mass Transfer, 50 (2007) 5328-5333. 
[12] Baumeister K.J., Hamill T.D., Schoessow G.J.: A generalized correlation of vaporization times of drops in film boiling on flat plate, Proc. 3rd Int. Heat Transfer Conf., vol. 4, 1966.

[13] Burton J.C., Sharpe A.L., Veen van der R.C.A., Franco A., Nagel S.R.: The geometry of the vapor layer under a Leidenfrost drop, Phys. Rev. Letters, 109 (2012) 074301-1-4.

[14] Orzechowski T., Wciślik S.: Analysis of the droplet film boiling heat transfer under ambient pressure, Energy Conversion Management, 76 (2013) 918-924.

[15] Orzechowski T., Wciślik S.: Instantaneous heat transfer for large drops levitating over a hot surface, Int. J. Heat Mass Transfer, 73 (2014) 110-117.

\section{MAPPING OF WATER DROPS EVAPORATION UNDER LEIDENFROST CONDITIONS}

\section{S u m m a r y}

The evaporation of large liquid droplets of a mass of $\sim 1 \mathrm{~g}$ in the stable boiling conditions at atmospheric pressure is discussed. Evaporation of a drop of liquid floating over the hot surface with a temperature above the Leidenfrost point is very difficult phenomenon to describe theoretically in detail. The study indicates the complexity of the interrelated processes of heat and mass transfer, which leads to intense convective subsurface movements inside the drop. A strong variation of a thermal field of the upper surface of the drop has been seen. There can be noted that at the average drop temperature of $\sim 91^{\circ} \mathrm{C}$ the difference between extreme temperatures can reach $\sim 8 \mathrm{~K}$.

Keywords: film boiling, Leidenfrost drop, thermovision camera, shape instability, convection movements

DOI: $10.7862 / \mathrm{rm} .2014 .7$

Otrzymano/received: 15.05.2014

Zaakceptowano/accepted: 27.05.2014 